\title{
O novo quadro legal da Propriedade Industrial em Portugal
}

\author{
The new legal framework of Industrial Property in Portugal
}

\author{
LUÍSA FILIPE FREITAS ${ }^{1}$
}

luisafreitas@jpg-associados.com

GALILEU - REVISTA DE DIREITO E ECONOMIA - e-ISSN 2184-1845

Volume XX $\cdot 1^{\text {st }}$ January Janeiro $-30^{\text {TH }}$ June Junho $2019 \cdot$ pp. 153-157

DOI: ???

A Propriedade Industrial desempenha um papel determinante para o crescimento económico, surgindo como um elemento regulador numa economia de mercado em que necessariamente se estabelecem relações de concorrência, assegurando a proteção dos investimentos realizados pelas empresas em atividades de investigação e desenvolvimento (I\&D) e criando as condições necessárias ao desenvolvimento tecnológico, à competitividade das economias e à promoção da inovação.

Consciente deste desiderato, o XXI Governo Constitucional aprovou, através do Decreto-Lei n. ${ }^{\circ}$ 110/2018 de 10 de dezembro, o novo Código da Propriedade Industrial, revogando o anterior que vigorava desde 2003, transpondo para o ordenamento jurídico interno a Diretiva (EU) 2015/2436 do Parlamento Europeu e do Conselho de 16 de dezembro de 2015 que aproxima as legislações dos Estados-Membros em matéria de marcas e a Diretiva (EU) 2016/943 do Parlamento Europeu e do Conselho, de 8 de junho de 2016, relativa à proteção de know-how e de informações comerciais confidenciais (segredos comerciais) contra a sua aquisição, utilização e divulgação ilegais.

Nesta senda, o regime de marcas sofreu importantes alterações, sendo de destacar a desnecessidade de representação gráfica, devendo as marcas ser representadas por forma a que seja possível determinar o seu objeto de proteção de um modo claro e preciso. Com o novo Código foi introduzido o regime de invocação da falta de uso sério como meio de defesa em processos de oposição e de recusa provisória, possibilidade que fica excluída no decurso de processos de oposição apresentados antes da entrada em vigor do mesmo.

1 Mestranda em Direito das Empresas e do Trabalho no ISCTE-IUL Business School. Advogada. 
Também a nível de duração da marca se constatam alterações, passando o prazo de dez anos a contar-se a partir da data de apresentação do pedido e não da sua concessão (cfr. artigo 247. ${ }^{\circ}$ do novo Código da Propriedade Industrial).

Outra novidade importante prende-se com alteração do pedido de marca após a sua publicação, a qual só será admitida para limitar a lista de produtos ou serviços ou para corrigir o nome ou a morada indicados no requerimento, erros de expressão ou de transcrição, ou erros manifestos e desde que a alteração não afete substancialmente a marca ou não alargue a lista de produtos ou serviços (cfr. artigo 228. ${ }^{\circ}$ do novo Código da Propriedade Industrial).

Relativamente às marcas cujo pedido de registo foi efetuado de má-fé, constituindo, quando invocado por um interessado, fundamento de recusa, estas encontram-se agora sujeitas ao regime da nulidade, como resulta do artigo $259 .^{\circ} \mathrm{n} . .^{\circ} 1$ do novo Código da Propriedade Industrial.

Por último, de referir ainda neste âmbito que o novo Código da Propriedade Industrial vem clarificar o regime jurídico das marcas coletivas e das marcas de certificação ou garantia.

Procedendo como se referiu supra à transposição da Diretiva (EU) 2016/943 do Parlamento Europeu e do Conselho, de 8 de junho de 2016, relativa à proteção de know-how e de informações comerciais confidenciais (segredos comerciais) contra a sua aquisição, utilização e divulgação ilegais, no novo Código da Propriedade Industrial aprovado pelo diploma em análise foi concedida uma tutela acrescida aos segredos comerciais. Esta matéria passa a estar autonomizada do regime da concorrência desleal no Título III, do Capítulo 2 do Código, sob a epígrafe "Proteção dos segredos comerciais".

Neste sentido o novo Código vem prever os requisitos cumulativos necessários preencher para que a informação possa ser entendida como segredo comercial e, nessa medida, protegida como tal. Em suma, como resulta do artigo $313 .{ }^{\circ}$ n. ${ }^{\circ}$, a informação tem de ser secreta, ter valor comercial pelo facto de ser secreta e ter sido objeto de diligências razoáveis, atendendo às circunstâncias, por parte da pessoa que detém legalmente o controlo das informações, no sentido de a manter secreta.

A violação de segredo comercial protegido constitui um ilícito contraordenacional, tendo-se optado pela não criminalização da mesma, como decorre do artigo $331 .^{\circ}$ do novo Código da Propriedade Industrial.

Outra novidade consiste na preservação da confidencialidade dos segredos comerciais em processos judiciais, prevista no artigo $352 .^{\circ}$ do novo Código da Propriedade Industrial.

De referir que as disposições referentes à matéria de proteção de segredos comerciais entraram em vigor no dia 1 de janeiro de 2019.

Como resulta do preâmbulo do Decreto-Lei n. ${ }^{\circ}$ 110/2018 de 10 de dezembro, o referido diploma veio ainda simplificar e clarificar os procedimentos administrativos relativos à 
atribuição, manutenção e cessação de vigência dos direitos de propriedade industrial previstos no Código da Propriedade Industrial e introduzir mecanismos que permitem fortalecer o sistema de proteção dos direitos e imprimir maior eficácia à repressão das infrações.

Neste sentido, assistimos a um conjunto alargado de alterações noutros domínios além das marcas e dos segredos comerciais, como a área das infrações aos direitos de propriedade industrial, das patentes e dos modelos de utilidade.

$\mathrm{Na}$ área das infrações aos direitos de propriedade industrial cumpre-nos destacar, relativamente aos ilícitos criminais, a previsão como ilícito criminal da violação do exclusivo do logotipo (vg. artigo $323 .^{\circ}$ do novo Código da Propriedade Industrial), bem como a criação de novos tipos de crimes por violação de marca, de que é exemplo a importação, exportação, distribuição, colocação no mercado ou armazenamento com essas finalidades de produtos com marcas contrafeitas ou imitadas, agora plasmado na alínea d) do artigo $320 .^{\circ}$ do novo Código da Propriedade Industrial.

No âmbito dos ilícitos contraordenacionais, um especial enfoque para a previsão de um novo tipo de ilícito de violação de segredo comercial protegido (vide artigo $331 .^{\circ}$ do novo Código da Propriedade Industrial).

Relativamente ao exercício do direito de queixa, continuando o procedimento por crimes previstos no Código da Propriedade Industrial a depender de queixa, o novo diploma vem esclarecer no seu artigo $328 .^{\circ}$ que o órgão de polícia criminal ou a entidade policial que tiver conhecimento de factos que possam constituir crimes previstos neste Código deve informar, no prazo de 10 dias, o titular do direito de queixa dos factos de que teve conhecimento e dos objetos apreendidos, informando-o ainda sobre o prazo para o exercício do direito de queixa.

Outra novidade importante neste âmbito está relacionada com os custos de armazenagem e de destruição dos artigos apreendidos, os quais deixam de estar na esfera do titular do direito violado, passando a ser considerados encargos do processo, sendo a responsabilidade pelo seu pagamento apurada nos termos previstos na lei processual penal (vide artigo 361. ${ }^{\circ}$ do novo Código da Propriedade Industrial).

Merecem um especial enfoque as alterações introduzidas no domínio das patentes, designadamente no que se refere aos pedidos provisórios de patente, cujo prazo de pesquisa efetuada pelo Instituto Nacional da Propriedade Industrial (INPI) a pedido do requerente é reduzido de doze para dez meses, o que representa uma melhoria considerável atento o prazo de doze meses prescrito como prazo máximo para a sua conversão em pedido definitivo de patente (vide artigo 63. ${ }^{\circ}$ do novo Código da Propriedade Industrial). Outra novidade a destacar é a limitação plasmada no n. ${ }^{\circ} 3$ do artigo $72 .^{\circ}$ do novo Código da Propriedade Industrial no âmbito das alterações do pedido de patente, o qual não poderá ser alterado de tal forma que contenha matéria técnica que exceda o seu conteúdo à data de pedido. 
No âmbito dos direitos conferidos pela patente, no novo quadro legal a norma do artigo $102 .^{\circ}$ n. 3 vem prever o direito de impedir a violação indireta da patente, i.e., de impedir a terceiros a oferta ou a disponibilização a qualquer pessoa que não tenha o direito de explorar a invenção patenteada dos meios para executá-la.

De referir ainda que, no que respeita à titularidade das invenções realizadas em consequência de atividades de investigação por trabalhadores ou colaboradores e de desenvolvimento no seio de uma pessoa coletiva pública, o novo Código da Propriedade Industrial passa a prever no seu artigo 59. ${ }^{\circ}$ que as mesmas pertencem à pessoa coletiva pública, a qual poderá, porém, transmitir a titularidade ao inventor, podendo reservar-se o direito de ficar titular de uma licença de exploração não exclusiva, intransmissível e gratuita. Em todo o caso, o inventor terá o direito de participar nos benefícios económicos auferidos pela pessoa coletiva pública na exploração ou na cessão dos direitos de patente.

$\mathrm{Na}$ área dos modelos de utilidade cumpre-nos sublinhar o facto de com o novo Código da Propriedade Industrial deixar de ser possível a apresentação de pedidos de modelo de utilidade sem exame substantivo. Efetivamente, no quadro legal anterior o Instituto Nacional da Propriedade Industrial apenas promovia o exame da invenção a pedido do requerente ou de qualquer interessado. Atualmente a promoção do exame da invenção é obrigatória, como resulta do artigo $132 .{ }^{\circ} \mathrm{n} .{ }^{\circ} 1$ do novo Código da Propriedade Industrial. De referir que esta alteração não se aplica aos pedidos de modelo de utilidade sem exame que tenham sido apresentados antes da entrada em vigor do Decreto-Lei n. ${ }^{\circ}$ 110/2018 de 10 dezembro. Não obstante, sempre que o titular do modelo de utilidade que tenha sido concedido sem exame pretenda exercer os direitos que o mesmo confere arbitral ou judicialmente, é obrigado a requerer previamente junto do INPI a realização de exame ${ }^{2}$.

Além das alterações ao Código da Propriedade Industrial, o Decreto-Lei n. ${ }^{\circ}$ 110/2018 de 10 de dezembro veio introduzir alterações à Lei da Organização do Sistema Judiciário ${ }^{3}$. Neste âmbito assistimos a uma diminuição do leque de matérias da competência do Tribunal da Propriedade Intelectual, passando para a esfera do INPI a decisão a proferir sobre a declaração de nulidade e de anulação de registos de desenhos ou modelos, de marcas, de logótipos, de denominação de origem, de indicações geográficas e de recompensas, com a ressalva de que tal pedido não tenha sido deduzido em reconvenção (matéria que se mantém da competência do Tribunal da Propriedade Intelectual)4. Esta alteração consta igualmente do novo Código da Propriedade Industrial no seu artigo $34 .^{\circ}$ e entra em vigor no dia 1 de julho

2 Neste sentido o artigo $6 .^{\circ}$ do Decreto-Lei n. ${ }^{\circ} 110 / 2018$ de 10 de dezembro.

3 Lei n. ${ }^{\circ}$ 62/2013, de 26 de Agosto na redação dada pela Lei n. ${ }^{\circ}$ 19/2019, de 19 de fevereiro.

4 Cfr. artigo $111 .^{\circ}$ n. ${ }^{\circ} 1$ alínea c) da Lei n. ${ }^{\circ}$ 62/2013, de 26 de Agosto na redação dada pelo Decreto-Lei n. ${ }^{\circ} 110 / 2018$ de 10 de dezembro ora em análise e artigo $34 .^{\circ} \mathrm{n} .{ }^{\circ} 2$ do novo Código de Propriedade Industrial. 
de 2019, sendo certo porém que as disposições anteriormente vigentes se continuam a aplicar aos prazos para pedidos de anulabilidade que estejam a correr àquela data e às ações de nulidade e anulação já intentadas no Tribunal da Propriedade Intelectual5.

Por outro lado, o diploma em análise veio prever como sendo da competência do Tribunal da Propriedade Intelectual conhecer das ações em que a causa de pedir verse sobre a prática de infração de segredos comerciais em matéria de propriedade industrial ${ }^{6}$, autonomizando esta dos atos de concorrência desleal. O que ademais resulta da redação do novo Código de Propriedade Industrial que, como se referiu supra, vem criar no Título III, Capítulo 2, um quadro normativo específico para a proteção dos segredos comerciais.

O Decreto-Lei n. ${ }^{\circ}$ 110/2018 de 10 de dezembro vem ainda revogar o regime da arbitragem necessária, instituído pela Lei n. ${ }^{\circ}$ 62/2011, de 12 de dezembro, para a composição de litígios emergentes da invocação de direitos de propriedade industrial, relacionados com medicamentos de referência e medicamentos genéricos, estabelecer neste domínio o carácter voluntário da arbitragem. Destarte, mantendo-se a necessidade de o titular de direitos de propriedade industrial agir no prazo de 30 dias a contar da publicitação pelo INFARMED - Autoridade Nacional do Medicamento e Produtos de Saúde, IP do pedido de autorização ou registo de introdução no mercado, desde 9 de janeiro de $2019^{7}$ este passou a poder optar por seguir a via arbitral mediante acordo da contraparte, ou judicial junto do Tribunal da Propriedade Intelectual.

Por último, de destacar, ainda nesta sede, a inclusão no preceito em análise da possibilidade de no processo arbitral ser invocada e reconhecida a invalidade da patente com meros efeitos interpartes. Esta alteração veio ao encontro da decisão do Tribunal Constitucional que, no acórdão n. ${ }^{\circ}$ 251/2017, de 7 de julho ${ }^{8}$, julgou inconstitucional a norma interpretativamente extraível do artigo $2 .^{\circ}$ da Lei n. ${ }^{\circ}$ 62/2011, de 12 de dezembro e artigos $35 .^{\circ} \mathrm{n} .{ }^{\circ} 1 \mathrm{e}$ $101 .^{\circ} \mathrm{n} .^{\circ} 2$ do Código da Propriedade Industrial à data em vigor, no sentido de não admitir a defesa, por exceção, mediante invocação de tal invalidade, por violação do princípio da proibição de indefesa plasmado no artigo 20. ${ }^{\circ}$ Constituição da República Portuguesa conjugado com o seu artigo $18 .^{\circ}$, n..$^{\circ}$, prejudicando de modo desproporcionado o direito à defesa do requerente do pedido de autorização de introdução no mercado.

5 Cfr. artigo $10 .{ }^{\circ}$ do Decreto-Lei n. ${ }^{\circ} 110 / 2018$ de 10 de dezembro.

6 Cfr. artigo $111 .^{\circ}$ n. ${ }^{\circ} 1$ alínea j) da Lei n. ${ }^{\circ} 62 / 2013$, de 26 de Agosto na redação dada pelo Decreto-Lei n. ${ }^{\circ}$ 110/2018 de 10 de dezembro ora em análise.

7 Data em que as alterações à Lei n. ${ }^{\circ} 62 / 2011$, de 12 de dezembro entraram em vigor, de acordo com o artigo $16 .{ }^{\circ} \mathrm{n} .{ }^{\circ} 3$ do Decreto-Lei n. ${ }^{\circ} 110 / 2018$ de 30 de dezembro.

8 Processo n. ${ }^{\circ}$ 297/16, em que foi Relator a Conselheira Maria de Fátima Mata-Mouros, diploma consultado em http://www.tribunalconstitucional.pt a 17 de julho de 2019. 